\title{
AN ITERATIVE ALGORITHM FOR GENERALIZED NONLINEAR VARIATIONAL INCLUSIONS WITH RELAXED STRONGLY ACCRETIVE MAPPINGS IN BANACH SPACES
}

\author{
A. H. SIDDIQI and RAIS AHMAD
}

Received 7 August 2003

\begin{abstract}
We use Nadler's theorem and the resolvent operator technique for $m$-accretive mappings to suggest an iterative algorithm for solving generalized nonlinear variational inclusions with relaxed strongly accretive mappings in Banach spaces. We prove the existence of solutions for our inclusions without compactness assumption and the convergence of the iterative sequences generated by the algorithm in real Banach spaces. Some special cases are also discussed.
\end{abstract}

2000 Mathematics Subject Classification: 49J40, 49J53, 47H06.

1. Introduction. Variational inequality theory provides us with a unified framework for dealing with a wide class of problems arising in elasticity, structural analysis, economics, physical and engineering sciences, and so forth, see, for example, [2, 6, 13, 14] and references therein. A useful and important generalization of variational inequalities is a mixed type variational inequality containing nonlinear term. Due to the presence of the nonlinear term, the projection method cannot be used to study the existence and algorithm of solutions for the mixed type variational inequalities. In 1994, Hassouni and Moudafi [14] used the resolvent operator technique for maximal monotone mappings to study a class of mixed type variational inequalities with single-valued mappings called variational inclusion and developed a perturbed algorithm for finding approximate solutions to the mixed variational inequalities. Adly [1], Ahmad and Ansari [2], Ahmad et al. [3], Chang et. al. [9], Ding [11, 12], and Huang [15, 16, 17] studied some important generalizations of variational inclusions in different directions. Very recently, Chang [8], Chang et al. [10], and Huang [17] introduced and studied some classes of set-valued variational inclusions in real Banach spaces. Also, Alber and Yao [5] introduced a new class of generalized multivalued covariational inequalities in Banach spaces.

Inspired and motivated by the recent research work going on in this field, we consider in this paper the generalized nonlinear variational inclusions in Banach spaces. An iterative algorithm is defined for solving generalized nonlinear variational inclusions in Banach spaces by using Nadler's theorem and the resolvent operator technique. Using the characterization of the resolvent operator, we have shown that the generalized nonlinear variational inclusions in Banach spaces are equivalent to some kinds of fixed point problems. We also establish that the approximate solutions obtained by our algorithm converge to the exact solution of the generalized nonlinear variational inclusion problem in Banach spaces. 
2. Preliminaries and formulations. Throughout this paper, we assume that $E$ is a real Banach space whose norm is denoted by $\|\cdot\|, E^{*}$ is the topological dual of $E, C B(E)$ is the family of all nonempty, closed, and bounded subsets of $E, D(\cdot, \cdot)$ is the Hausdorff metric on $C B(E)$ defined by

$$
D(A, B)=\max \left\{\sup _{x \in A} d(x, B), \sup _{y \in B} d(A, y)\right\},
$$

where $d(x, B)=\inf _{y \in B} d(x, y), d(A, y)=\inf _{x \in A} d(x, y), d$ is the metric on $E$ induced by the norm $\|\cdot\|,\langle\cdot, \cdot\rangle$ is the duality pairing between $E$ and $E^{*}, D(T)$ is the domain of $T$, and $J: E \rightarrow 2^{E^{*}}$ is the normalized duality mapping defined by

$$
J(x)=\left\{f \in E^{*}:\langle x, f\rangle=\|x\| \cdot\|f\|,\|f\|=\|x\|\right\}, \quad x \in E .
$$

We recall that the uniform convexity [5] of the space $E$ means that for any given $\epsilon>0$, there exists $\delta>0$ such that for all $x, y \in E,\|x\| \leq 1,\|y\|<1$, and $\|x-y\|=\epsilon$, we have

$$
\|x+y\| \leq 2(1-\delta) .
$$

The function

$$
\delta_{B}(\epsilon)=\inf \left\{1-\frac{\|x+y\|}{2}:\|x\|=1,\|y\|=1,\|x-y\|=\epsilon\right\}
$$

is called the modulus of the convexity of the space $E$.

The uniform smoothness of the space $E$ means that for any given $\epsilon>0$, there exists $\delta>0$ such that

$$
\frac{\|x+y\|+\|x-y\|}{2}-1 \leq \epsilon\|y\|
$$

holds. The function

$$
\rho_{B}(t)=\sup \left\{\frac{\|x+y\|+\|x-y\|}{2}-1:\|x\|=1,\|y\|=t\right\}
$$

is called the modulus of the smoothness of the space $E$.

We observe that the space $E$ is uniformly convex if and only if $\delta_{B}(\epsilon)>0$ for all $\epsilon>0$, and it is uniformly smooth if and only if $\lim _{t \rightarrow 0} t^{-1} \rho_{B}(t)=0$. The following inequalities will be used for the proof of our main result.

Proposition 2.1 [4]. Let $E$ be a uniformly smooth Banach space and let $J: E \rightarrow 2^{E^{*}}$ be the normalized duality mapping. Then for any $x, y \in E$,

(i) $\|x+y\|^{2} \leq\|x\|^{2}+2\langle y, j(x+y)\rangle$, for all $j(x+y) \in J(x+y)$;

(ii) $\langle x-y, j(x)-j(y)\rangle \leq 2 c^{2} \rho_{B}(4\|x-y\| / c)$, where $c=\sqrt{\left(\|x\|^{2}+\|y\|^{2}\right) / 2}$.

DEFINITION 2.2 [5]. Let $J: E \rightarrow 2^{E^{*}}$ be the normalized duality mapping. The mapping $f: E \rightarrow E$ is said to be

(1) strongly accretive if there exists a constant $\alpha>0$ such that

$$
\langle f(x)-f(y), j(x-y)\rangle \geq \alpha\|x-y\|^{2}, \quad \forall x, y \in E, j(x-y) \in J(x-y) ;
$$


(2) relaxed strongly accretive with respect to the set-valued mapping $T: E \rightarrow C B(E)$ if there exists a constant $v \geq 0$ such that

$$
\langle f(u)-f(v), j(x-y)\rangle \leq-v\|x-y\|^{2},
$$

for all $x, y \in E, u \in T(x), v \in T(y)$, and $j(x-y) \in J(x-y)$.

REMARK 2.3. If $E=H$ is a Hilbert space, then the notion of relaxed strongly accretive coincides with that of relaxed Lipschitz (see [19]).

DEFINITION 2.4 [17]. Let $J: E \rightarrow 2^{E^{*}}$ be the normalized duality mapping. The setvalued mapping $A: D(A) \subset E \rightarrow 2^{E}$ is said to be

(1) accretive if for any $x, y \in D(A)$, there exists $j(x-y) \in J(x-y)$ such that for all $u \in A(x), v \in A(y)$,

$$
\langle u-v, j(x-y)\rangle \geq 0
$$

(2) strongly accretive, $k \in(0,1)$, if for any $x, y \in D(A)$, there exists $j(x-y) \in$ $J(x-y)$ such that for all $u \in A(x), v \in A(y)$,

$$
\langle u-v, j(x-y)\rangle \geq k\|x-y\|^{2}
$$

(3) $m$-accretive if $A$ is accretive and $(I+\rho A)(D(A))=E$ for every (equivalently, for some) $\rho>0$, where $I$ is the identity mapping (equivalently, if $A$ is accretive and $(I+A)(D(A))=E)$

REMARK 2.5 [9]. If $E=H$ is a Hilbert space, then $A: D(A) \subset H \rightarrow 2^{H}$ is an $m$-accretive mapping if and only if $A: D(A) \subset H \rightarrow 2^{H}$ is a maximal monotone mapping.

LEMMA 2.6 [17]. Let $g: E \rightarrow E$ be a continuous and $k$-strongly accretive mapping. Then $g$ maps E onto E.

For a given set-valued mapping $T: E \rightarrow C B(E)$, single-valued mappings $f, g: E \rightarrow E$, and $m$-accretive mapping $A: E \rightarrow 2^{E}$, we consider the following problem:

(i) GNVIP: find $x \in E, w \in T(x)$ such that $0 \in g(x)-f(w)+A(g(x))$. It is called the generalized nonlinear variational inclusion problem (GNVIP) in Banach spaces.

Now we present some particular cases of the GNVIP which show that our GNVIP is a more general and unified problem.

SPEcial CASES. (1) If $E=H$ is a Hilbert space and $A=\partial \varphi$, where $\varphi: H \rightarrow R \cup$ $\{+\infty\}$ is a proper convex lower semicontinuous function on $H$ and $\partial \varphi$ denotes the subdifferential of function $\varphi$, then GNVIP is equivalent to finding $x \in H$ and $w \in T(x)$ such that $g(x) \cap \operatorname{dom}(\partial \varphi) \neq \varnothing$ and

$$
\langle g(x)-f(w), y-g(x)\rangle \geq \varphi(g(x))-\varphi(y), \quad \forall y \in H,
$$


which was introduced and studied by Ahmad and Ansari [2]. If $\varphi(x)=I_{K(x)}$, the indicator function of a closed convex set $K$ in $H$ defined by

$$
I_{K(x)}= \begin{cases}0, & x \in K, \\ +\infty, & \text { otherwise, }\end{cases}
$$

then problem (2.11) reduces to a problem considered by Verma [19].

(2) If $E=H$ is a Hilbert space and $A: H \rightarrow 2^{H}$ is a maximal monotone mapping, then by Remark 2.5, $A$ is also an $m$-accretive mapping. Thus problem GNVIP is equivalent to finding $x \in H$ and $w \in T(x)$ such that

$$
0 \in g(x)-f(w)+A(g(x))
$$

which is a variant form of the problem considered by Huang [16].

(3) If $g(x)-f(w)=w$, then GNVIP is equivalent to finding $x \in H$ and $w \in T(x)$ such that

$$
0 \in w+A(g(x))
$$

which was studied and introduced by Huang [15].

\section{Iterative algorithms}

Definition 3.1 [7]. Let $A: D(A) \subset E \rightarrow 2^{E}$ be an $m$-accretive mapping. For any $\rho>0$, the mapping $R_{\rho}^{A}: E \rightarrow D(A)$ associated with $A$ defined by

$$
R_{\rho}^{A}(u)=(I+\rho A)^{-1}(u), \quad u \in E,
$$

is called the resolvent operator.

DEFINITION 3.2. The resolvent operator $R_{\rho}^{A}$ is said to be a retraction on $D(A)$ if $(I+\rho A)^{-1} \circ(I+\rho A)^{-1}=(I+\rho A)^{-1}$.

REMARK 3.3. It is well known that $R_{\rho}^{A}$ is a single-valued and nonexpansive mapping (see [8]).

To propose the algorithm for computing the approximate solution of GNVIP, we convert GNVIP into a fixed point problem.

LEMMA 3.4. The pair $(x, w)$ with $x \in E$ and $w \in T(x)$ is a solution of GNVIP if and only if $(x, w)$ satisfies the following relation:

$$
g(x)=R_{\rho}^{A}[g(x)-\rho(g(x)-f(w))],
$$

where $\rho>0$ is a constant, $R_{\rho}^{A}=(I+\rho A)^{-1}$ is the resolvent operator associated with $A$, and $I$ is the identity operator on $E$. 
Proof. From the definition of the resolvent operator $R_{\rho}^{A}$ associated with $A$ and relation (3.2), we have

$$
\begin{aligned}
g(x) & =R_{\rho}^{A}[g(x)-\rho(g(x)-f(w))] \\
& =(I+\rho A)^{-1}[g(x)-\rho(g(x)-f(w))],
\end{aligned}
$$

and therefore

$$
g(x)-\rho(g(x)-f(w)) \in g(x)+\rho A(g(x)) .
$$

The above relations hold if and only if $x \in E$ and $w \in T(x)$ such that

$$
0 \in g(x)-f(w)+A(g(x))
$$

We now invoke Lemmas 3.4 and 2.6 and Nadler's theorem [18] to suggest the following algorithm for solving GNVIP in the setting of real Banach spaces.

Algorithm 3.5. Suppose that $g: E \rightarrow E$ is a continuous and $k$-strongly accretive mapping. For any given $x_{0} \in E$, we take $w_{0} \in T\left(x_{0}\right)$ and we let

$$
x_{1}=x_{0}-g\left(x_{0}\right)+R_{\rho}^{A}\left[g\left(x_{0}\right)-\rho\left(g\left(x_{0}\right)-f\left(w_{0}\right)\right)\right] .
$$

Since $w_{0} \in T\left(x_{0}\right) \in C B(E)$, by Nadler [18], there exists $w_{1} \in T\left(x_{1}\right)$ such that

$$
\left\|w_{0}-w_{1}\right\| \leq(1+1) D\left(T\left(x_{0}\right), T\left(x_{1}\right)\right) .
$$

Let

$$
x_{2}=x_{1}-g\left(x_{1}\right)+R_{\rho}^{A}\left[g\left(x_{1}\right)-\rho\left(g\left(x_{1}\right)-f\left(w_{1}\right)\right)\right] .
$$

Again by Nadler [18], there exists $w_{2} \in T\left(x_{2}\right)$ such that

$$
\left\|w_{1}-w_{2}\right\| \leq\left(1+\frac{1}{2}\right) D\left(T\left(x_{1}\right), T\left(x_{2}\right)\right) .
$$

Continuing the above process inductively, we can obtain the sequences $\left\{x_{n}\right\}$ and $\left\{w_{n}\right\}$ such that

$$
\begin{gathered}
x_{n+1}=x_{n}-g\left(x_{n}\right)+R_{\rho}^{A}\left[g\left(x_{n}\right)-\rho\left(g\left(x_{n}\right)-f\left(w_{n}\right)\right)\right], \\
w_{n} \in T\left(x_{n}\right), \quad\left\|w_{n}-w_{n+1}\right\| \leq\left(1+\frac{1}{n+1}\right) D\left(T\left(x_{n}\right), T\left(x_{n+1}\right)\right),
\end{gathered}
$$

where $n=0,1,2, \ldots$ and $\rho>0$ is a constant.

If $g(x)-f(w)=w$, then from Algorithm 3.5, we derive the following algorithm to find the approximate solution for problem (2.14) proposed by Huang [17]. 
Algorithm 3.6. Suppose that $g: E \rightarrow E$ is a continuous and a $k$-strongly accretive mapping. For any given $x_{0} \in E$, compute the sequence $\left\{x_{n}\right\}$ and $\left\{w_{n}\right\}$ by iterative scheme such that

$$
\begin{gathered}
g\left(x_{n+1}\right)=R_{\rho}^{A}\left[g\left(x_{n}\right)-\rho w_{n}\right], \\
w_{n} \in T\left(x_{n}\right), \quad\left\|w_{n}-w_{n+1}\right\| \leq\left(1+\frac{1}{n+1}\right) D\left(T\left(x_{n}\right), T\left(x_{n+1}\right)\right),
\end{gathered}
$$

where $n=0,1,2, \ldots$

4. Existence and convergence results. In this section, we prove the existence of a solution for GNVIP and the convergence of iterative sequences generated by Algorithm 3.5.

Definition 4.1. The mapping $g: E \rightarrow E$ is said to be Lipschitz continuous if there exists a constant $\delta>0$ such that

$$
\|g(x)-g(y)\| \leq \delta\|x-y\|, \quad \forall x, y \in E
$$

Definition 4.2. The set-valued mapping $T: E \rightarrow C B(E)$ is said to be $D$-Lipschitz continuous if there exists a constant $\eta>0$ such that

$$
D(T(x), T(y)) \leq \eta\|x-y\|, \quad \forall x, y \in E .
$$

THEOREM 4.3. Let $E$ be a real Banach space with the module of smoothness $\tau_{B(t)} \leq C t^{2}$ for some $C>0$. Let $A: E \rightarrow 2^{E}$ be an $m$-accretive mapping, let $g, f: E \rightarrow E$ be single-valued mappings, and let $T: E \rightarrow C B(E)$ be a set-valued mapping. Suppose that the following conditions are satisfied:

(i) $g$ is both $k$-strongly accretive and Lipschitz continuous with constant $\delta>0$;

(ii) $f$ is both relaxed strongly accretive with respect to $T$ with constant $v \geq 0$ and Lipschitz continuous with constant $\lambda>0$;

(iii) $T$ is D-Lipschitz continuous with constant $\eta>0$.

If $(I+\rho A)^{-1} \circ(I+\rho A)^{-1}=(I+\rho A)^{-1}$ and

$$
\begin{aligned}
\mid \rho- & \frac{1+v+P(1-2 P)}{1+2 v+64 C \lambda^{2} \eta^{2}-P^{2}} \mid \\
& <\frac{\sqrt{[(v+1)+P(2 P-1)]^{2}-4 P(1-P)\left(1+2 v+64 C \lambda^{2} \eta^{2}-P^{2}\right)}}{1+2 v+64 C \lambda^{2} \eta^{2}-P^{2}}, \\
1+v & >P(2 P-1)+\sqrt{4 P(1-P)\left(1+2 v+64 C \lambda^{2} \eta^{2}-P^{2}\right)}, \\
1+2 v & +64 C \lambda^{2} \eta^{2}>P^{2} \quad \text { for } P=\sqrt{1-2 K+64 C \lambda^{2}}<\frac{1}{2},
\end{aligned}
$$

then there exists a solution ( $x, w)$ of GNVIP, and the iterative sequences $\left\{x_{n}\right\}$ and $\left\{w_{n}\right\}$ generated by Algorithm 3.5 converge strongly to $x$ and $w$ in $E$, respectively. 
Proof. From Algorithm 3.5, we have

$$
\left\|x_{n+1}-x_{n}\right\|=\left\|x_{n}-x_{n-1}-\left(g\left(x_{n}\right)-g\left(x_{n-1}\right)\right)+R_{\rho}^{A}\left(z\left(x_{n}\right)\right)-R_{\rho}^{A}\left(z\left(x_{n-1}\right)\right)\right\|,
$$

where $z\left(x_{n}\right)=g\left(x_{n}\right)-\rho\left(g\left(x_{n}\right)-f\left(w_{n}\right)\right)$. Since the resolvent operator $R_{\rho}^{A}$ is nonexpansive, we have

$$
\begin{aligned}
\left\|R_{\rho}^{A}\left(z\left(x_{n}\right)\right)-R_{\rho}^{A}\left(z\left(x_{n-1}\right)\right)\right\| \\
\leq\left\|z\left(x_{n}\right)-z\left(x_{n-1}\right)\right\| \\
=\left\|(1-\rho)\left(g\left(x_{n}\right)-g\left(x_{n-1}\right)\right)+\rho\left(f\left(w_{n}\right)-f\left(w_{n-1}\right)\right)\right\| \\
\leq(1-\rho)\left\|x_{n}-x_{n-1}-\left(g\left(x_{n}\right)-g\left(x_{n-1}\right)\right)\right\| \\
\quad+\left\|(1-\rho)\left(x_{n}-x_{n-1}\right)+\rho\left(f\left(w_{n}\right)-f\left(w_{n-1}\right)\right)\right\| .
\end{aligned}
$$

From (4.4) and (4.5), we have

$$
\begin{aligned}
\left\|x_{n+1}-x_{n}\right\| \leq & \left\|x_{n}-x_{n-1}-\left(g\left(x_{n}\right)-g\left(x_{n-1}\right)\right)\right\|+\left\|R_{\rho}^{A}\left(z\left(x_{n}\right)\right)-R_{\rho}^{A}\left(z\left(x_{n-1}\right)\right)\right\| \\
\leq & \left\|x_{n}-x_{n-1}-\left(g\left(x_{n}\right)-g\left(x_{n-1}\right)\right)\right\| \\
& +(1-\rho)\left\|x_{n}-x_{n-1}-\left(g\left(x_{n}\right)-g\left(x_{n-1}\right)\right)\right\| \\
& +\left\|(1-\rho)\left(x_{n}-x_{n-1}\right)+\rho\left(f\left(w_{n}\right)-f\left(w_{n-1}\right)\right)\right\| \\
= & (2-\rho)\left\|x_{n}-x_{n-1}-\left(g\left(x_{n}\right)-g\left(x_{n-1}\right)\right)\right\| \\
& +\left\|(1-\rho)\left(x_{n}-x_{n-1}\right)+\rho\left(f\left(w_{n}\right)-f\left(w_{n-1}\right)\right)\right\| .
\end{aligned}
$$

Since $g$ is $k$-strongly accretive and Lipschitz continuous with constant $\delta>0$, and by Proposition 2.1, we have

$$
\begin{aligned}
\| x_{n} & -x_{n-1}-\left(g\left(x_{n}\right)-g\left(x_{n-1}\right)\right) \|^{2} \\
\leq & \left\|x_{n}-x_{n-1}\right\|^{2}+2\left\langle-\left(g\left(x_{n}\right)-g\left(x_{n-1}\right)\right), j\left(x_{n}-x_{n-1}-\left(g\left(x_{n}\right)-g\left(x_{n-1}\right)\right)\right\rangle\right. \\
= & \left.\left\|x_{n}-x_{n-1}\right\|^{2}+2\left\langle-\left(g\left(x_{n}\right)-g\left(x_{n-1}\right)\right), j\left(x_{n}-x_{n-1}\right)\right)\right\rangle \\
& +2\left\langle-\left(g\left(x_{n}\right)-g\left(x_{n-1}\right)\right), j\left(x_{n}-x_{n-1}-\left(g\left(x_{n}\right)-g\left(x_{n-1}\right)\right)\right)-j\left(x_{n}-x_{n-1}\right)\right\rangle \\
\leq & \left\|x_{n}-x_{n-1}\right\|^{2}-2 k\left\|x_{n}-x_{n-1}\right\|^{2}+4 d^{2} \rho B\left(\frac{4\left\|g\left(x_{n}\right)-g\left(x_{n-1}\right)\right\|}{d}\right) \\
\leq & \left\|x_{n}-x_{n-1}\right\|^{2}-2 k\left\|x_{n}-x_{n-1}\right\|^{2}+64 C\left\|g\left(x_{n}\right)-g\left(x_{n-1}\right)\right\|^{2} \\
\leq & \left(1-2 k+64 C \delta^{2}\right)\left\|x_{n}-x_{n-1}\right\|^{2} .
\end{aligned}
$$


Since $f$ is relaxed strongly accretive with respect to $T$ and with constant $v>0$, and Lipschitz continuous with constant $\lambda>0$, and $T$ is $D$-Lipschitz continuous with constant $\eta>0$, and by Proposition 2.1, we obtain

$$
\begin{aligned}
\|(1 & -\rho)\left(x_{n}-x_{n-1}\right)+\rho\left(f\left(w_{n}\right)-f\left(w_{n-1}\right)\right) \|^{2} \\
\leq & (1-\rho)^{2}\left\|x_{n}-x_{n-1}\right\|^{2} \\
& +2\left\langle\rho\left(f\left(w_{n}\right)-f\left(w_{n-1}\right)\right), j\left((1-\rho)\left(x_{n}-x_{n-1}\right)+\rho\left(f\left(w_{n}\right)-f\left(w_{n-1}\right)\right)\right)\right\rangle \\
= & (1-\rho)^{2}\left\|x_{n}-x_{n-1}\right\|^{2} \\
& +2\left\langle\rho\left(f\left(w_{n}\right)-f\left(w_{n-1}\right)\right), j\left((1-\rho)\left(x_{n}-x_{n-1}\right)+\rho\left(f\left(w_{n}\right)-f\left(w_{n-1}\right)\right)\right)\right. \\
& \left.\quad-j\left((1-\rho)\left(x_{n}-x_{n-1}\right)\right)\right\rangle \\
& +2\left\langle\rho\left(f\left(w_{n}\right)-f\left(w_{n-1}\right)\right), j\left((1-\rho)\left(x_{n}-x_{n-1}\right)\right)\right\rangle \\
= & (1-\rho)^{2}\left\|x_{n}-x_{n-1}\right\|^{2}+4 d^{2} \rho_{B}\left(\frac{4}{d}|\rho|\left\|f\left(w_{n}\right)-f\left(w_{n-1}\right)\right\|\right) \\
& +2 \rho(1-\rho)\left\langle f\left(w_{n}\right)-f\left(w_{n-1}\right), j\left(x_{n}-x_{n-1}\right)\right\rangle \\
\leq & (1-\rho)^{2}\left\|x_{n}-x_{n-1}\right\|^{2}-2 \rho(1-\rho) v\left\|x_{n}-x_{n-1}\right\|^{2} \\
& +64 C \rho^{2}\left\|f\left(w_{n}\right)-f\left(w_{n-1}\right)\right\|^{2} \\
\leq & {\left.\left[(1-\rho)^{2}-2 \rho(1-\rho) v\right]\left\|x_{n}-x_{n-1}\right\|\right|^{2} } \\
\leq & \left.(1-\rho)^{2}-2 \rho(1-\rho) v+64 C \rho^{2} \lambda^{2}\left(1+\frac{1}{n}\right)^{2} \eta^{2}\right]\left\|x_{n}-x_{n-1}\right\|^{2} . \\
& +64 C \rho^{2} \lambda^{2}\left(1+\frac{1}{n}\right)^{2} D^{2}\left(T\left(x_{n}\right), T\left(x_{n-1}\right)\right) \\
& {[(1-1)}
\end{aligned}
$$

From (4.6), (4.7), and (4.8), it follows that

$$
\left\|x_{n+1}-x_{n}\right\| \leq \theta_{n}\left\|x_{n}-x_{n-1}\right\|
$$

where

$$
\begin{aligned}
\theta_{n}= & (2-\rho)\left[1-2 k+64 C \delta^{2}\right]^{1 / 2} \\
& +\left[(1-\rho)^{2}-2 \rho(1-\rho) \nu+64 C \rho^{2} \lambda^{2}\left(1+\frac{1}{n}\right)^{2} \eta^{2}\right]^{1 / 2} .
\end{aligned}
$$

Letting

$$
\theta=(2-\rho)\left[1-2 k+64 C \delta^{2}\right]^{1 / 2}+\left[(1-\rho)^{2}-2 \rho(1-\rho) \nu+64 C \rho^{2} \lambda^{2} \eta^{2}\right]^{1 / 2},
$$


we know that $\theta_{n} \rightarrow \theta$ as $n \rightarrow \infty$. From condition (4.3), it follows that $\theta<1$. Hence $\theta_{n}<1$ for $n$ sufficiently large. Consequently, $\left\{x_{n}\right\}$ is a Cauchy sequence, and thus, converges to some $x \in E$. By Algorithm 3.5 and the $D$-Lipschitz continuity of $T$, it follows that

$$
\begin{aligned}
\left\|w_{n}-w_{n-1}\right\| & \leq\left(1+\frac{1}{n+1}\right) D\left(T\left(x_{n}\right), T\left(x_{n-1}\right)\right) \\
& \leq\left(1+\frac{1}{n}\right) \eta\left\|x_{n}-x_{n-1}\right\|,
\end{aligned}
$$

and hence $\left\{w_{n}\right\}$ is also a Cauchy sequence in $E$. Therefore, there exists $w \in E$ such that $w_{n} \rightarrow w$ as $n \rightarrow \infty$. Since $g, f$, and $R_{\rho}^{A}$ are continuous in $E$, we have

$$
x=x-g(x)+R_{\rho}^{A}(g(x)-\rho(g(x)-f(w))) .
$$

Finally, we prove that $w \in T(x)$. In fact, since $w_{n} \in T\left(x_{n}\right)$ and

$$
\begin{aligned}
d\left(w_{n}, T(x)\right) & \leq \max \left\{d\left(w_{n}, T(x)\right), \sup _{v \in T(x)} d\left(T\left(x_{n}\right), v\right)\right\} \\
& \leq \max \left\{\sup _{y \in T\left(x_{n}\right)} d(y, T(x)), \sup _{v \in T(x)} d\left(T\left(x_{n}\right), v\right)\right\} \\
& =D\left(T\left(x_{n}\right), T(x)\right),
\end{aligned}
$$

we have

$$
\begin{aligned}
d(w, T(x)) & \leq\left\|w-w_{n}\right\|+d\left(w_{n}, T(x)\right) \\
& \leq\left\|w-w_{n}\right\|+D\left(T\left(x_{n}\right), T(x)\right) \\
& \leq\left\|w-w_{n}\right\|+\eta\left\|x_{n}-x\right\| \longrightarrow 0 \quad(n \longrightarrow \infty)
\end{aligned}
$$

which implies that $d(w, T(x))=0$. Since $T(x) \in C B(E)$, it follows that $w \in T(x)$. Then by Lemma 3.4, we get the conclusion.

REMARK 4.4. Huang [17] studied a particular case of our problem (GNVIP) in the setting of real Banach spaces using the resolvent operator technique for $m$-acceretive mapping. By defining the resolvent operator to be a retraction mapping, we proved the existence of a solution of a more general problem than that considered by Huang [17].

The following result weakens the conditions of $f$ in Theorem 4.3.

THEOREM 4.5. Let $E$ be a real Banach space with the module of smoothness $\tau_{B(t)} \leq C t^{2}$ for some $C>0$. Let $A: E \rightarrow 2^{E}$ be an $m$-accretive mapping, let $g, f: E \rightarrow E$ be single-valued mappings, and let $T: E \rightarrow C B(E)$ be a set-valued mapping. Suppose that the following conditions are satisfied:

(1) $g$ is both $k$-strongly accretive and Lipschitz continuous with constant $\delta>0$;

(2) $f$ is Lipschitz continuous with constant $\lambda>0$;

(3) $T$ is D-Lipschitz continuous with constant $\eta>0$;

(4) $0<\left(1-2 K+64 C \delta^{2}\right)^{1 / 2}+(1-\rho) \delta+\rho \lambda \eta<1$. 
Then there exists a solution $(x, w)$ of GNVIP and the iterative sequences $\left\{x_{n}\right\}$ and $\left\{w_{n}\right\}$ generated by Algorithm 3.5 converge strongly to $x, w$ in $E$, respectively.

Proof. From Algorithm 3.5 and using the fact that the resolvent operator is nonexpansive, we have

$$
\begin{aligned}
& \left\|x_{n+1}-x_{n}\right\| \\
& =\| x_{n}-g\left(x_{n}\right)+R_{\rho}^{A}\left\{g\left(x_{n}\right)-\rho\left(g\left(x_{n}\right)-f\left(w_{n}\right)\right)\right\} \\
& \quad \quad-\left[x_{n-1}-g\left(x_{n-1}\right)+R_{\rho}^{A}\left\{g\left(x_{n-1}\right)-\rho\left(g\left(x_{n-1}\right)-f\left(w_{n-1}\right)\right)\right\}\right] \| \\
& \leq\left\|x_{n}-x_{n-1}-\left(g\left(x_{n}\right)-g\left(x_{n-1}\right)\right)\right\| \\
& \quad+\left\|(1-\rho)\left(g\left(x_{n}\right)-g\left(x_{n-1}\right)\right)+\rho\left(f\left(w_{n}\right)-f\left(w_{n-1}\right)\right)\right\| \\
& \leq\left\|x_{n}-x_{n-1}-\left(g\left(x_{n}\right)-g\left(x_{n-1}\right)\right)\right\|+(1-\rho)\left\|g\left(x_{n}\right)-g\left(x_{n-1}\right)\right\| \\
& \quad+\rho\left\|f\left(w_{n}\right)-f\left(w_{n-1}\right)\right\| .
\end{aligned}
$$

It follows from (4.8) that

$$
\left\|x_{n}-x_{n-1}-\left(g\left(x_{n}\right)-g\left(x_{n-1}\right)\right)^{2} \leq\left(1-2 k+64 C \delta^{2}\right)\right\| x_{n}-x_{n-1} \|^{2} .
$$

Also, it follows from the Lipschitz property of the corresponding functions that

$$
\begin{aligned}
\left\|g\left(x_{n}\right)-g\left(x_{n-1}\right)\right\| & =\delta\left\|x_{n}-x_{n-1}\right\|, \\
\left\|f\left(w_{n}\right)-f\left(w_{n-1}\right)\right\| & =\lambda\left\|w_{n}-w_{n-1}\right\| \\
& \leq \lambda\left(1+\frac{1}{n}\right) D\left(T\left(x_{n}\right), T\left(x_{n-1}\right)\right) \\
& \leq \lambda\left(1+\frac{1}{n}\right) \eta\left\|x_{n}-x_{n-1}\right\| \\
& =\lambda \eta\left\|x_{n}-x_{n-1}\right\| \quad(\text { as } n \rightarrow \infty) .
\end{aligned}
$$

From (4.8), (4.17), and (4.19), we have the following inequality:

$$
\left\|x_{n+1}-x_{n}\right\| \leq q\left\|x_{n}-x_{n-1}\right\|
$$

where $q=\left(1-2 k+64 C \delta^{2}\right)^{1 / 2}(1-\rho) \delta+\rho \lambda \eta$ and $0<q<1$ by condition (4). Consequently, $\left\{x_{n}\right\}$ is a Cauchy sequence in $E$. Then the result follows by using the same arguments of Theorem 4.3 .

ACKNOWLeDGMENT. A. H. Siddiqi would like to thank King Fahd University of Petroleum \& Minerals, Dhahran, Saudi Arabia, for providing excellent facilities for carrying out this work. 


\section{REFERENCES}

[1] S. Adly, Perturbed algorithms and sensitivity analysis for a general class of variational inclusions, J. Math. Anal. Appl. 201 (1996), no. 2, 609-630.

[2] R. Ahmad and Q. H. Ansari, An iterative algorithm for generalized nonlinear variational inclusions, Appl. Math. Lett. 13 (2000), no. 5, 23-26.

[3] R. Ahmad, A. Khaliq, and S. S. Irfan, Completely generalized nonlinear variational-like inclusions with noncompact set-valued mappings, Nonlinear Anal. Forum 7 (2002), no. 2, 159-166.

[4] Ya. Alber, Metric and generalized projection operators in Banach spaces: properties and applications, Theory and Applications of Nonlinear Operators of Accretive and Monotone Type, Lecture Notes in Pure and Appl. Math., vol. 178, Dekker, New York, 1996, pp. 15-50.

[5] Ya. Alber and J. C. Yao, Algorithm for generalized multi-valued co-variational inequalities in Banach spaces, Funct. Differ. Equ. 7 (2000), no. 1-2, 5-13.

[6] C. Baiocchi and A. Capelo, Variational and Quasivariational Inequalities, A WileyInterscience Publication, John Wiley \& Sons, New York, 1984.

[7] V. Barbu, Nonlinear Semigroups and Differential Equations in Banach Spaces, Noordhoff International Publishing, Leiden, 1976.

[8] S. S. Chang, Set-valued variational inclusions in Banach spaces, J. Math. Anal. Appl. 248 (2000), no. 2, 438-454.

[9] S. S. Chang, Y. J. Cho, B. S. Lee, and I. H. Jung, Generalized set-valued variational inclusions in Banach spaces, J. Math. Anal. Appl. 246 (2000), no. 2, 409-422.

[10] S. S. Chang, J. K. Kim, and K. H. Kim, On the existence and iterative approximation problems of solutions for set-valued variational inclusions in Banach spaces, J. Math. Anal. Appl. 268 (2002), no. 1, 89-108.

[11] X-P. Ding, Perturbed proximal point algorithms for generalized quasivariational inclusions, J. Math. Anal. Appl. 210 (1997), no. 1, 88-101.

[12] X-P. Ding and C. L. Luo, Perturbed proximal point algorithms for general quasi-variationallike inclusions, J. Comput. Appl. Math. 113 (2000), no. 1-2, 153-165.

[13] P. T. Harker and J. S. Pang, Finite-dimensional variational inequality and nonlinear complementarity problems: a survey of theory, algorithms and applications, Math. Program., Ser. B 48 (1990), no. 2, 161-220.

[14] A. Hassouni and A. Moudafi, A perturbed algorithm for variational inclusions, J. Math. Anal. Appl. 185 (1994), no. 3, 706-712.

[15] N. J. Huang, Generalized nonlinear variational inclusions with noncompact valued mappings, Appl. Math. Lett. 9 (1996), no. 3, 25-29.

[16] _ A new completely general class of variational inclusions with noncompact valued mappings, Comput. Math. Appl. 35 (1998), no. 10, 9-14.

[17]___ A new class of generalized set-valued implicit variational inclusions in Banach spaces with an application, Comput. Math. Appl. 41 (2001), no. 7-8, 937-943.

[18] S. B. Nadler Jr., Multi-valued contraction mappings, Pacific J. Math. 30 (1969), 475-488.

[19] R. U. Verma, Iterative algorithms for variational inequalities and associated nonlinear equations involving relaxed Lipschitz operators, Appl. Math. Lett. 9 (1996), no. 4, 61-63.

A. H. Siddiqi: Department of Mathematical Sciences, King Fahd University of Petroleum \& Minerals, Dhahran 31261, Saudi Arabia

E-mail address: ahasan@kfupm.edu.sa

Rais Ahmad: Department of Mathematics, Aligarh Muslim University, Aligarh 202002, India E-mail address: raisain@ycos.com 


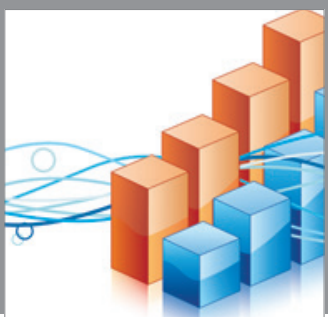

Advances in

Operations Research

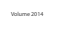

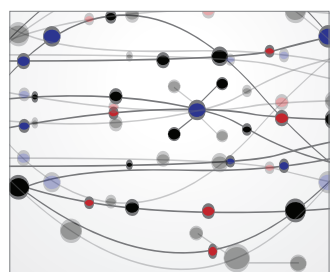

\section{The Scientific} World Journal
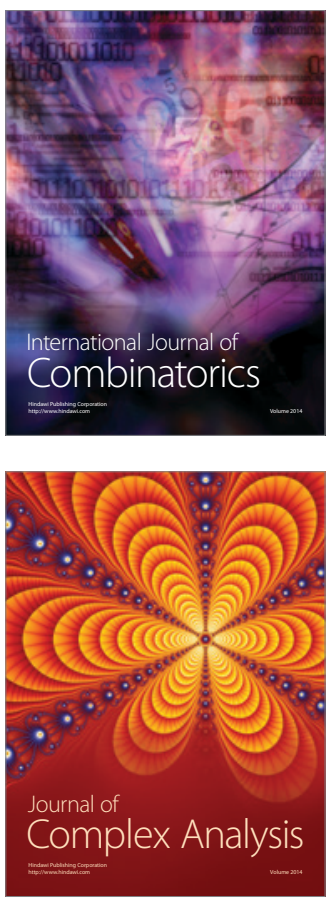

International Journal of

Mathematics and

Mathematical

Sciences
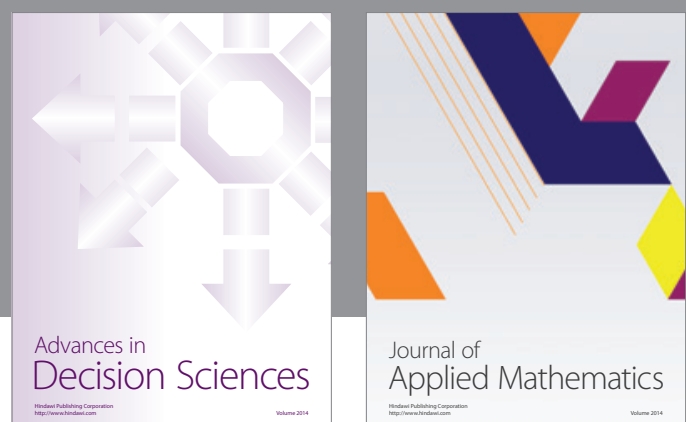

Journal of

Applied Mathematics
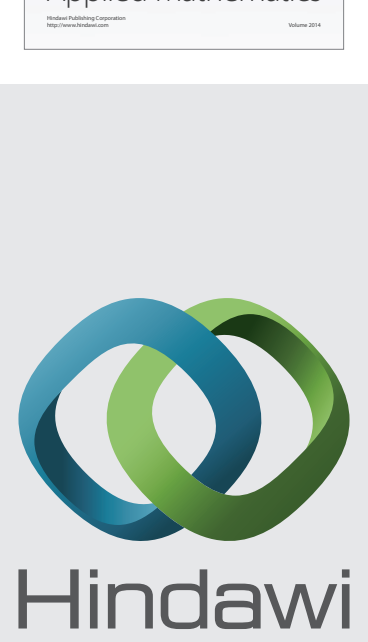

Submit your manuscripts at http://www.hindawi.com
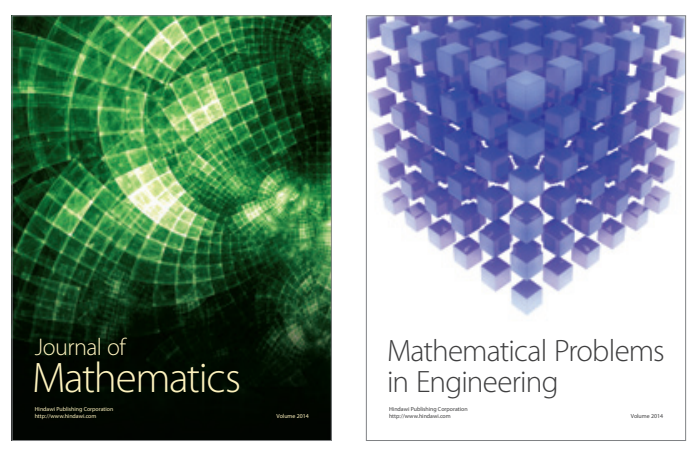

Mathematical Problems in Engineering
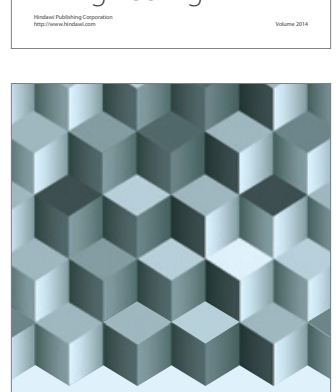

Journal of

Function Spaces
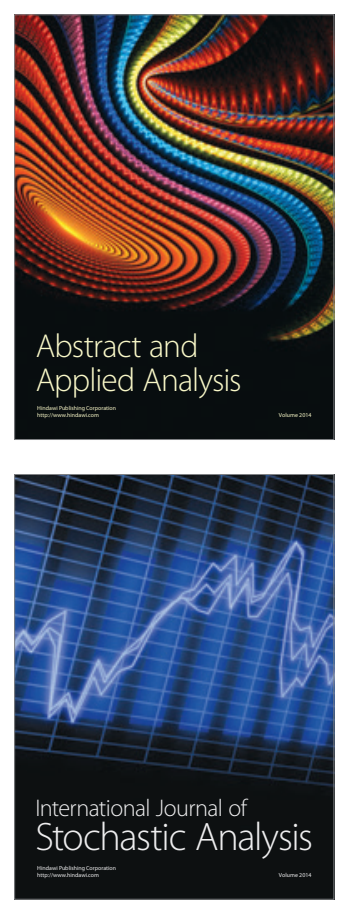

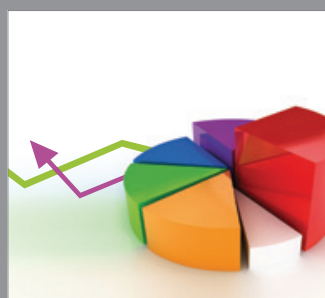

ournal of

Probability and Statistics

Promensencen
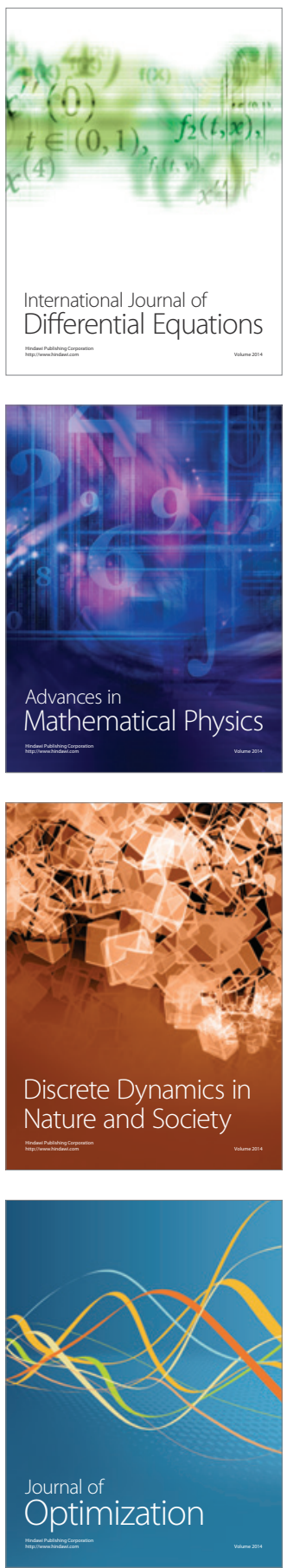